\title{
Lung-to-lung circulation times during exercise in heart
}

\section{failure}

Norman R. Morris ${ }^{1}$, Eric M. Snyder ${ }^{2}$, Kenneth C. Beck ${ }^{2}$ and Bruce D. Johnson ${ }^{2}$.

${ }^{1}$ School of Physiotherapy and Exercise Science, Griffith University, Gold Coast campus

Australia. ${ }^{2}$ Division of Cardiovascular Diseases, Mayo Clinic, Rochester, MN, USA.

Corresponding author:

Norman R Morris Ph.D

School of Physiotherapy and Exercise Science

Gold Coast Campus, Griffith University

Queensland 4222, Australia

Telephone: +61 (0)7 55528921

Facsimile: +61 (0)7 55528674

E-mail: n.morris@griffith.edu.au

Running head: Circulation Time During Exercise in Heart Failure 


\section{ABSTRACT}

Circulation time (the transit time for a bolus of blood through the circulatory system) is a potential index of cardiac dysfunction in HF. In healthy subjects, circulation time falls as cardiac output $(\mathrm{Q})$ rises during exercise, however little is known about this index in HF. In this study we examined the relationship between lung-to-lung circulation time $(\mathrm{LLCT})$ during exercise in ten $\mathrm{HF}(53 \underline{14} \mathrm{yr}$, resting $\mathrm{EF}=23 \pm 8 \%)$ and control subjects $(51 \pm 18 \mathrm{yr})$. We hypothesized that HF patients would have slower LLCT times during exercise when compared to control subjects. Each subject completed two identical incremental exercise tests during which LLCT was measured in one test and Q measured in the other. Q was measured using the open circuit $\mathrm{C}_{2} \mathrm{H}_{2}$ washin technique and circulation time measured using an inert gas technique. In HF patients and control subjects, LLCT decreased and Q increased from rest (HF:LLCT $=53.6 \pm 8.2 \mathrm{~s}, \mathrm{Q}=4.3 \pm 1.1 \mathrm{I} \cdot \mathrm{min}^{-1}$; Control: $\mathrm{LLCT}=$ $\left.55.3 \pm 10.9 \mathrm{~s}, \mathrm{Q}=4.5 \pm 0.5 \mathrm{I} \cdot \mathrm{min}^{-1}\right)$ to peak exercise $\left(\mathrm{HF}: \mathrm{LLCT}=20.6 \pm 3.9^{*} \mathrm{~S}, \mathrm{Q}=\right.$ $8.8+2.5^{\star} \mathrm{I} \cdot \mathrm{min}^{-1} ;$ Control: $\mathrm{LLCT}=14.9 \pm 2.4 \mathrm{~s}, \mathrm{Q}=16.5 \pm 1 \cdot 2 \mathrm{I} \cdot \mathrm{min}^{-1} * \mathrm{P}<0.05$ vs Control). LLCT was significantly $(P<0.05)$ slower for the HF group when compared to the control group during submaximal exercise and at peak exercise. However, at a fixed Q the HF subjects had a faster LLCT. We hypothesise that the faster LLCT at a fixed Q for HF patients, may be the result of a more intensive peripheral vasoconstriction of non-active beds and a better redistribution of blood flow. 


\section{INTRODUCTION}

Circulation time is the time taken for blood to travel through the vascular system. A prolonged or lengthening of the circulation time is an often-cited clinical feature of chronic heart failure (HF) (17) and a potential index of worsening disease (1-3, 6). Recently we also demonstrated that HF patients with longer resting lung-to-lung circulation times (LLCT) (i.e. time taken for blood to travel from the pulmonary circulation, through the vascular system and back again) had poorer peak exercise capacity $\left(\mathrm{VO}_{2 \text { peak }}\right)$ and cardiac function (9).

Currently little is known of what happens to LLCT during exercise in HF. In healthy individuals, the cardiovascular response to incremental exercise is characterized by an increase in cardiac output (Q) and a redistribution of blood flow away from inactive vascular beds toward exercising muscle, both leading to a progressive shortening of the circulation time $(11,13)$. In individuals with known cardiac dysfunction such as HF patients one would predict that there would be an attenuated fall in the LLCT time during exercise. However, since these patients also have a more aggressive vasoconstriction $(7,8)$, the LLCT may be preserved.

Few studies have examined changes in LLCT during exercise. One reason for the paucity of studies published to date, has been the difficulty in measuring changes in circulation time during exercise. We have recently developed a simple, noninvasive method for estimating LLCT using the soluble gas acetylene $\left(\mathrm{C}_{2} \mathrm{H}_{2}\right)$. Using this method, we are able to determine the time taken for a bolus of $\mathrm{C}_{2} \mathrm{H}_{2}$ to travel from the lungs, through the systemic circulation and then back to the lungs i.e. the lung-to-lung circulation time. This technique was developed from methods for 
determining cardiac output (Q) using soluble gases(15), where recirculation is a well-described phenomenon.

Therefore, the aim of this study was to compare the changes in LLCT during incremental exercise in a group of HF patients with a group of healthy, age and gender-matched controls. We hypothesized that HF patients would have a prolonged LLCT when compared to healthy controls for a given work load or oxygen consumption. To test this hypothesis we measured LLCT and Q during incremental exercise in $10 \mathrm{HF}$ patients and 10 healthy controls. 


\section{METHODS}

Subject Details: The study was approved by the Mayo Clinic Institutional review board and all subjects completed a written consent form prior to commencing. Ten HF patients (3 females) and ten healthy control subjects ( 3 females) participated in this study. All HF patients had a history of ischemic or dilated cardiomyopathy, stable HF symptoms ( $>3$ months), duration of HF symptoms $>3$ months, left ventricular ejection fraction $(E F) \leq 40 \%$ and a body mass index $(B M I)<35 \mathrm{~kg} \cdot \mathrm{m}^{-2}$. The characteristics of the HF and control subjects are outlined in Table 1. Patients were recruited from the Mayo Heart Failure Clinic or the Cardiovascular Health Clinic (a preventive and rehabilitative center). Control subjects had normal pulmonary function, were normotensive and had no signs or symptoms of ischemia during an incremental exercise test to exhaustion.

Study Design: After familiarization and consent, each subject undertook two incremental exercise tests on an electronically braked cycle ergometer (Lode, Excalibur Sport, Gronigen, Netherlands). During the first test, classical gas exchange measures were made (e.g., oxygen uptake) along with Q. During the second exercise test LLCT was measured. The two incremental exercise tests were undertaken on separate days at approximately the same time of the day.

Incremental Exercise Test: Each subject completed a step protocol on the cycle ergometer which took approximately 12 minutes to complete. Subjects initially commenced unloaded cycling for a warm up period of 3-4 min following which the load was increased by approximately 20-25 Watts every 3 minutes for the HF patients and 30-60W every 3 minutes for the control subjects. The size of each 
increment in the load was determined prior to the exercise test and was based on the individual's previous exercise history and body size with individuals that were more physically active and larger undertaking greater increments.

During the incremental exercise test, oxygen uptake $\left(\mathrm{VO}_{2}\right)$ was measured breathby-breath using a metabolic measuring system (CPX-D, Medical Graphics Corporation, St. Paul, MN, USA). Heart rate and rhythm were monitored throughout (MedGraphics $\mathrm{CardiO}_{2}$, St. Paul, MN, USA) the exercise test. The gas exchange and heart rate data were averaged over $30-s$ intervals. Peak exercise values were calculated as the average of the two highest consecutive 30 -s values obtained prior to termination of exercise. Systolic (SBP) and diastolic (DBP) blood pressure were measured by auscultation at each stage of exercise with the same investigator measuring blood pressure throughout.

Cardiac Output was measured at each incremental exercise stage using the open circuit acetylene washin technique (4). This method has previously been validated with direct FICK method in healthy adults (4). Subjects breathed through a pneumotach connected to a non-rebreathing Y valve (Hans Rudolph, KC, MO). The inspiratory port of the non-rebreathing $Y$ valve was connected to a pneumatic switching valve (Hans Rudolph, KC, MO) that allowed switching between room air and a normoxic test gas mixture reservoir containing $0.65 \% \mathrm{C}_{2} \mathrm{H}_{2}, 9 \%$ helium. Gases were sampled using a mass spectrometer (Perkins Elma, MGA 1100) integrated with custom designed analysis software for the assessment of Q. At the onset of inspiration, subjects were switched from room air to the test gas mixture for 8-10 breaths to allow for the washin of $\mathrm{C}_{2} \mathrm{H}_{2}$ and the estimation of $\mathrm{Q}$. 
Circulation Time Measurement: Lung-to-lung circulation time was measured using an acetylene technique which we have previously described (9). Briefly, during this procedure, each subject inhaled a single breath of a $0.65 \% \mathrm{C}_{2} \mathrm{H}_{2}, 9.0 \%$ Helium $(\mathrm{He})$, normoxic gas mix. The subject then continued to breathe room air normally. Acetylene is an inert gas that is highly soluble into the blood. Helium is an insoluble tracer gas that is used to account for any breath-by-breath variation in the distribution of $\mathrm{C}_{2} \mathrm{H}_{2}$ within the lung. Following inhalation, the $\mathrm{P}_{\mathrm{ET}} \mathrm{C}_{2} \mathrm{H}_{2} / \mathrm{He}$ will fall as a function of the distribution of $\mathrm{C}_{2} \mathrm{H}_{2}$ into the pulmonary circulation and subsequently, the systemic circulation. At the point that a significant amount of $\mathrm{C}_{2} \mathrm{H}_{2}$ is recirculated, i.e. re-enters the pulmonary circulation from the right side of the heart, $\mathrm{P}_{\mathrm{ET}} \mathrm{C}_{2} \mathrm{H}_{2} / \mathrm{He}$ will start to rise. Using methods described previously (9) we defined LLCT from time of the first inhalation of $\mathrm{C}_{2} \mathrm{H}_{2}$ to the first point in which $\mathrm{P}_{E T} \mathrm{C}_{2} \mathrm{H}_{2} / \mathrm{He}$ started to rise again. The intra class correlation coefficients for repeated measures of resting LLCT at rest and during exercise was 0.95 (95\% confidence interval 0.82-0.99) (9).

Derived measurements: Arterial venous oxygen difference $\left(\mathrm{a}-\mathrm{v}_{\mathrm{O} 2}\right)$ was derived from the measures of oxygen uptake $\left(\mathrm{VO}_{2}\right)$ and $\mathrm{Q}$ using the Fick equation where $\mathrm{a}-\mathrm{V}_{\mathrm{O} 2}$ was equal to the ratio of $\mathrm{VO}_{2}$ to $\mathrm{Q}$. Systemic vascular conductance was determined from the ratio of $\mathrm{Q}$ and mean arterial blood (MAP) pressure at rest and each stage of the exercise test. Mean arterial pressure was calculated as $0.33^{\star}(\mathrm{SBP}-\mathrm{DBP})+\mathrm{DBP}$.

Statistical Analysis: All data is presented as mean \pm standard deviation (SD). Group differences were assessed using independent ttests. Changes in all other dependent measures during incremental exercise were evaluated using a one way 
repeated measures analysis of variance with the main effects being groups (HF vs control) and time. Bonferroni post-hoc tests were used when significant main effects were identified. Relationships between variables were assessed using Pearson correlation coefficients. The statistical significance was set at $\mathrm{P}<0.05$. 


\section{RESULTS}

The peak exercise responses for the HF and control subjects are presented in Table 2. At peak exercise, the $\mathrm{HF}$ subjects had a significantly lower $\mathrm{VO}_{2 \text { peak, }}$ $H R_{\text {peak, }}$ peak power, peak $\mathrm{Q}$ and SVpeak.

During the incremental exercise test, each subject completed at least 3 submaximal workload stages and one maximal workload. The changes in LLCT, Q and vascular conductance as a percentage of the peak power are shown in Figure 1 (Panels a-c). For both HF patients and control subjects, LLCT (Panel a) decreased from rest to peak exercise. LLCT was significantly $(P<0.05)$ longer (slower) for the HF group when compared to the control group during submaximal exercise (stages 2 and 3) and at peak exercise.

Q increased significantly from rest to peak exercise for both HF patients and control subjects. During submaximal (stages 2 and 3 ) and maximal exercise, $Q$ was significantly lower for the HF group when compared to the control group.

For both groups vascular conductance increased from rest and throughout exercise (Figure 1, panel c). However, for the HF group, the rise in vascular conductance during exercise was significantly less than that for the control group during submaximal exercise (stages 2 and 3 ) and at peak exercise.

The correlations between LLCT, Q and vascular conductance for the control and HF subjects are shown in Figure 2. There was a similar and significant correlation between LLCT and Q and between LLCT and vascular conductance for both groups. 
Changes in the LLCT as a function of the rise in Q are shown in Figure 3. As expected, there was a fall in the LLCT as Q rose during exercise for both groups. However, at a similar Q the HF subjects had a shorter (faster) LLCT. For example, at a $\mathrm{Q}$ of $8 \mathrm{I} \cdot \mathrm{min}^{-1}$ (iso cardiac output line, Figure 3), HF patients had a faster LLCT when compared to control subjects. 


\section{DISCUSSION}

This study is an extension of our previous work using LLCT as an index of the severity of $\mathrm{HF}(9)$. In the current study we found that LLCT fell during exercise for both HF and control subjects. We have previously shown that LLCT falls during exercise in healthy subjects (9). In a much earlier study, Sowton and colleagues (13) reported that recirculation time fell during exercise in a group of patients reported as having 'myocardial ischaemia'. In Sowton's (13) study recirculation time was measured using a labeled dye (indocyanine green) introduced into the pulmonary artery. Both lung-to-arterial and total recirculation time were measured. Lung-to-arterial circulation time was determined by taking downstream blood samples from the radial artery while total recirculation time was determined by sampling downstream in the pulmonary artery. While Sowton's and colleagues (13) subjects were not classified as HF, the fact that there was evidence of myocardial ischaemia suggests that there may have been some degree of cardiac dysfunction in this group.

Similar to our results, Sowton's (13) study found that individuals with myocardial ischaemia had longer lung-to-arterial and total circulation times when compared to healthy subjects at rest and during exercise. Hemodynamically, the fall in LLCT for both groups during exercise is due in part to an increase in Q (9). LLCT will fall with an increase in $\mathrm{Q}$ as a result of an increase blood flow velocity (10) resulting in faster uptake of $\mathrm{C}_{2} \mathrm{H}_{2}$ in the pulmonary circulation and faster transit of $\mathrm{C}_{2} \mathrm{H}_{2}$ through the arterial and venous circulations. When exercising at the same relative exercise intensity, we found that HF patients had a lower Q and a prolonged LLCT when 
compared to healthy subjects. Hence, the lower Q for HF patients during exercise contributes to the longer LLCT.

However, a comparison of the LLCT for the HF and healthy subjects at a fixed Q (Figure 3) found that HF patients had a faster LLCT. This suggests that when exercising at the same Q, HF patients must redistribute flow so that there is a faster return of blood to the right side of the heart when compared to control subjects.

For the LLCT to be faster during exercise at a similar Q for HF patients, the majority of $\mathrm{C}_{2} \mathrm{H}_{2}$ must be distributed into an arterial path with faster transit times and lower vascular resistances and a venous path that favors the return of blood to the right side of the heart. One possible explanation for the faster LLCT is that HF patients aggressively increase the vascular resistance of inactive vascular beds and redirect blood flow away from these beds and toward metabolically active vascular beds with a lower vascular resistance where there are faster transit times. The redistribution of blood flow away from inactive vascular beds (such as the renal and splachnic vascular beds) during exercise is well described (10) and while total systemic conductance increases, this increase is the result of a marked increase in conductance of the active skeletal muscle (10). Inactive vascular beds have a sympathetically mediated decrease in conductance (increase resistance) resulting in a redirection of blood flow to the exercising skeletal muscle vascular beds (10). Our results show that HF patients have a smaller rise in vascular conductance during exercise, suggesting that there is a greater general degree of vasoconstriction of vascular beds (10). This greater vasoconstriction could result in a greater redirection of blood flow to metabolically active beds. 
Redistribution of blood flow during exercise appears to be an important mediator of the exercise response in HF, albeit a controversial one. Yamabe et al (18) reported that HF was associated with a redistribution of blood flow away from inactive vascular beds to exercising muscles during one-legged incremental exercise. In this study, the ratio of exercising leg blood flow to $\mathrm{Q}$ increased during incremental recumbent exercise. Simultaneous measurements of blood flow to the inactive leg showed the ratio of non-exercising leg blood flow to $\mathrm{Q}$ decreased during incremental exercise which Yamabe et al (18) interpreted as a redistribution of blood flow away from inactive vascular beds.

On the other hand, Sullivan et al (14) reported that blood flow to the inactive leg during upright cycling was maintained at the expense of blood flow to the active leg when compared to healthy individuals. As such, these authors concluded that blood flow is not preferentially redistributed during exercise in HF.

While the there is still some debate regarding the presence of a marked redistribution of blood flow during exercise in $\mathrm{HF}$, there is clear evidence that $\mathrm{HF}$ patients aggressively vasoconstrict inactive vascular beds during exercise. Recent studies have shown that reflex renal vasoconstriction is exaggerated in both magnitude and duration during dynamic exercise in HF patients $(7,8)$. In turn there is an increased activation of the renin-angiotensin system $(5,16)$ and an amplification of the already upregulated neurohumoral response seen in HF (5). Sinnoway and colleagues(12) showed that mechanically and chemically sensitive afferents in the exercising muscle are more likely to fire earlier and more often during dynamic exercise thereby amplifying the sympathetic nervous system response to exercise. 
This study is not without limitations due to the non-invasive measures used to determine dependent measures. The open circuit method for measuring Q has been validated in healthy younger and older subjects using direct Fick (4). However the technique has not been validated in HF patients as such this may represent a potential limitation of the project.

In conclusion, this study found that LLCT falls during exercise in both HF and healthy subjects. The fall in LLCT can in part be explained by increase for Q during exercise. However, LLCT at the same Q was faster for HF patients suggesting there was a redistribution of blood flow toward arterial and venous pathways that return blood to the right side of the heart faster. We hypothesise that this may be an example of the greater neurohumoral activation seen in HF patients.

\section{ACKNOWLEDGMENTS}

The authors of this study would like to thank Kathy O'Malley and Angela Heydmann for their assistance in the data collection and management of this project. This work was supported in part by National Institute of Health grant HL71478, the National Heart Foundation and the Heart Foundation Research Centre, Griffith University. 


\section{REFERENCES}

1. Andreas S. Central sleep apnea and chronic heart failure. Sleep 23 Suppl 4: S220223, 2000.

2. Caples SM, Wolk R, and Somers VK. Influence of cardiac function and failure on sleep-disordered breathing: evidence for a causative role. J Appl Physiol 99: 2433-2439, 2005.

3. Hall MJ, Xie A, Rutherford R, Ando S, Floras JS, and Bradley TD. Cycle length of periodic breathing in patients with and without heart failure. Am J Respir Crit Care Med 154: 376-381, 1996.

4. Johnson BD, Beck KC, Proctor DN, Miller J, Dietz NM, and Joyner MJ. Cardiac output during exercise by the open circuit acetylene washin method: comparison with direct Fick. J Appl Physiol 88: 1650-1658, 2000.

5. Joyner MJ. Congestive heart failure: more bad news from exercising muscle? Circulation 110: 2978-2979, 2004.

6. Lanfranchi PA, Braghiroli A, Bosimini E, Mazzuero G, Colombo R, Donner CF, and Giannuzzi P. Prognostic value of nocturnal Cheyne-Stokes respiration in chronic heart failure. Circulation 99: 1435-1440, 1999.

7. Middlekauff HR, Nitzsche EU, Hoh CK, Hamilton MA, Fonarow GC, Hage A, and Moriguchi JD. Exaggerated muscle mechanoreflex control of reflex renal vasoconstriction in heart failure. J Appl Physiol 90: 1714-1719, 2001.

8. Momen A, Bower D, Boehmer J, Kunselman AR, Leuenberger UA, and Sinoway LI. Renal blood flow in heart failure patients during exercise. Am J Physiol Heart Circ Physiol 287: H2834-2839, 2004. 
9. Morris NR, Snyder EM, Beck KC, Haseler LJ, Olson LJ, and Johnson BD. The relationship between resting lung-to-lung circulation time and peak exercise capacity in chronic heart failure patients. J Card Fail 13: 389-394, 2007.

10. Rowell LB. Circulatory adjustments to dynamic exercise and heat stress:

competing controls. In: Human Cardiovascular Control, edited by Rowell LB. Oxford, UK: Oxford University Press, 1993, p. 363-406.

11. Rowell LB. Human Cardiovascular Control. Oxford, UK: Oxford University Press, 1993.

12. Sinoway LI, and Li J. A perspective on the muscle reflex: implications for congestive heart failure. J Appl Physiol 99: 5-22, 2005.

13. Sowton E, Bloomfield D, Jones NL, Higgs BE, and Campbell EJ. Recirculation time during exercise. Cardiovasc Res 2: 341-345, 1968.

14. Sullivan MJ, Knight JD, Higginbotham MB, and Cobb FR. Relation between central and peripheral hemodynamics during exercise in patients with chronic heart failure. Muscle blood flow is reduced with maintenance of arterial perfusion pressure. Circulation 80: 769-781, 1989.

15. Triebwasser JH, Johnson RLJ, Burpo RP, Campbell JC, Reardon WC, and Blomqvist CG. Noninvasive determination of cardiac output by a modified acetylene rebreathing procedure utilizing mass spectrometer measurements. Aviation Space and Environmental Medicine 48: 203-209, 1977.

16. Vanhoutte PM. Endothelium-dependent responses and inhibition of angiotensinconverting enzyme. Clin Exp Pharmacol Physiol 23: S23-29, 1996.

17. Wolff CB, Checkley SK, Bhageerutty G, Bhatt H, Johnston A, Collier DJ, Tachtsidis I, Garvie N, Rosenberg ME, and Benjamin N. Circulation time in man from 
lung to periphery as an indirect index of cardiac output. Adv Exp Med Biol 566: 311-316, 2005.

18. Yamabe H, Itoh K, Yasaka Y, Takata T, and Yokoyama M. The role of cardiac output response in blood flow distribution during exercise in patients with chronic heart failure. Eur Heart J 16: 951-960, 1995. 

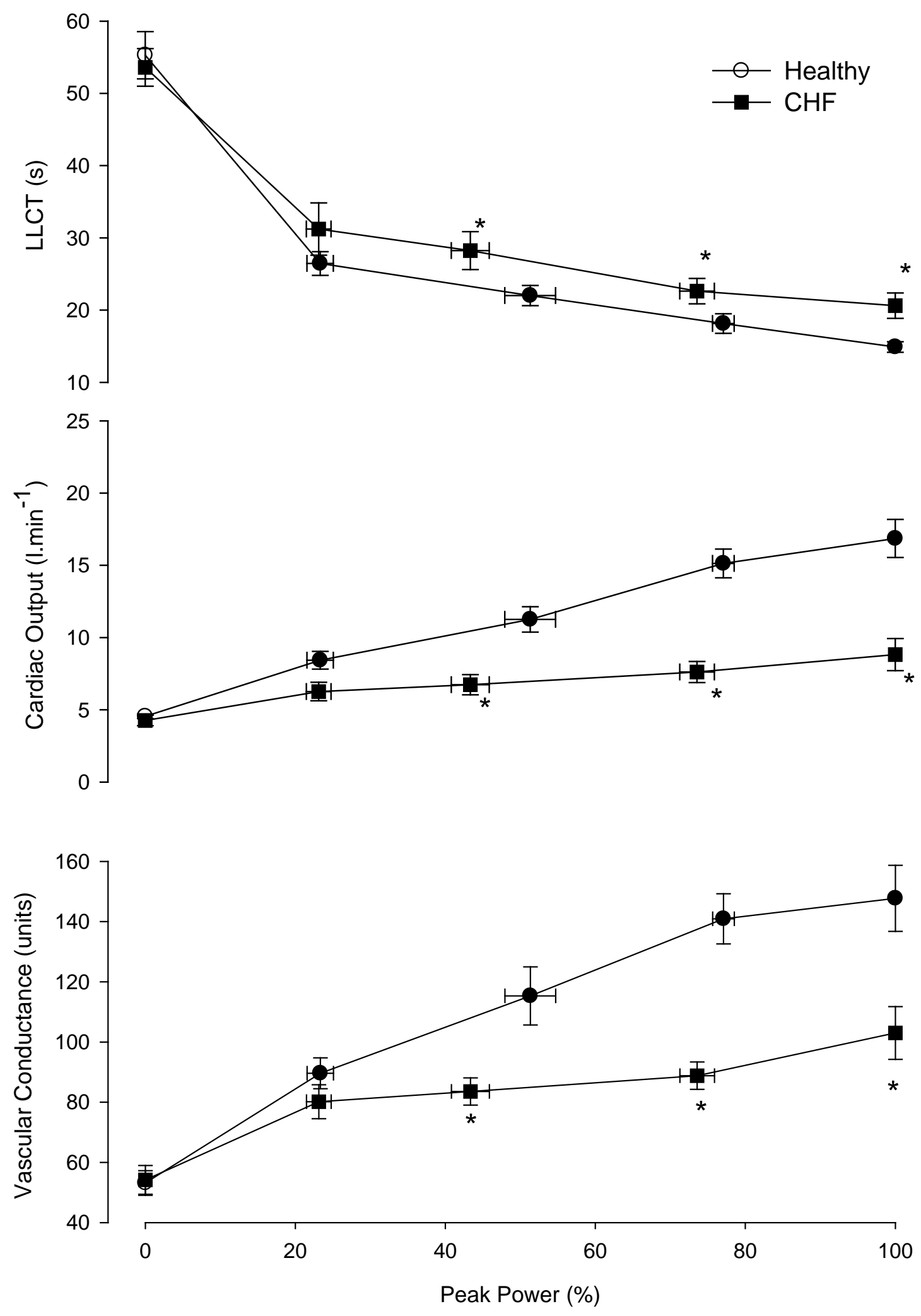

Figure 1 

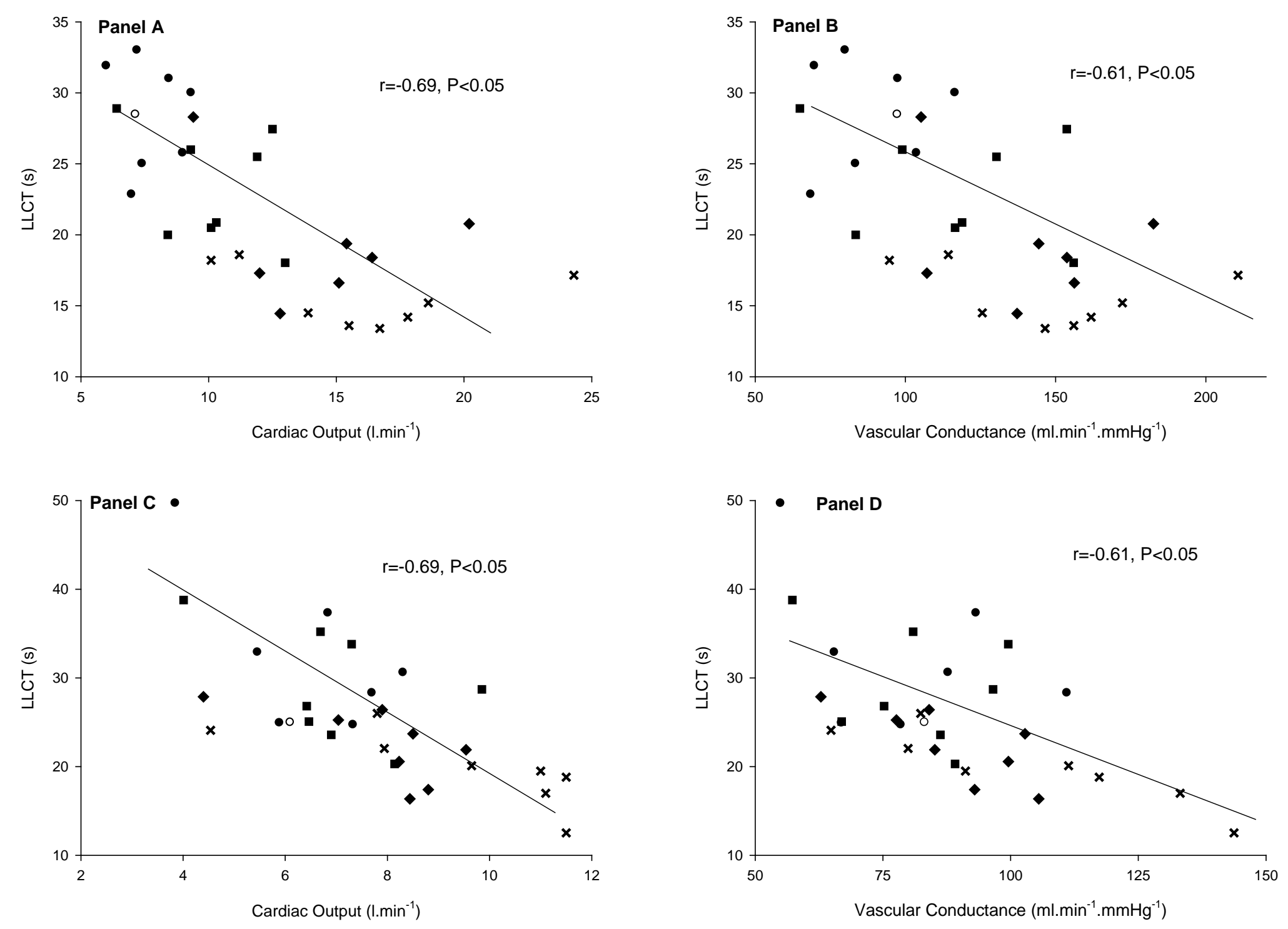

Figure 2 


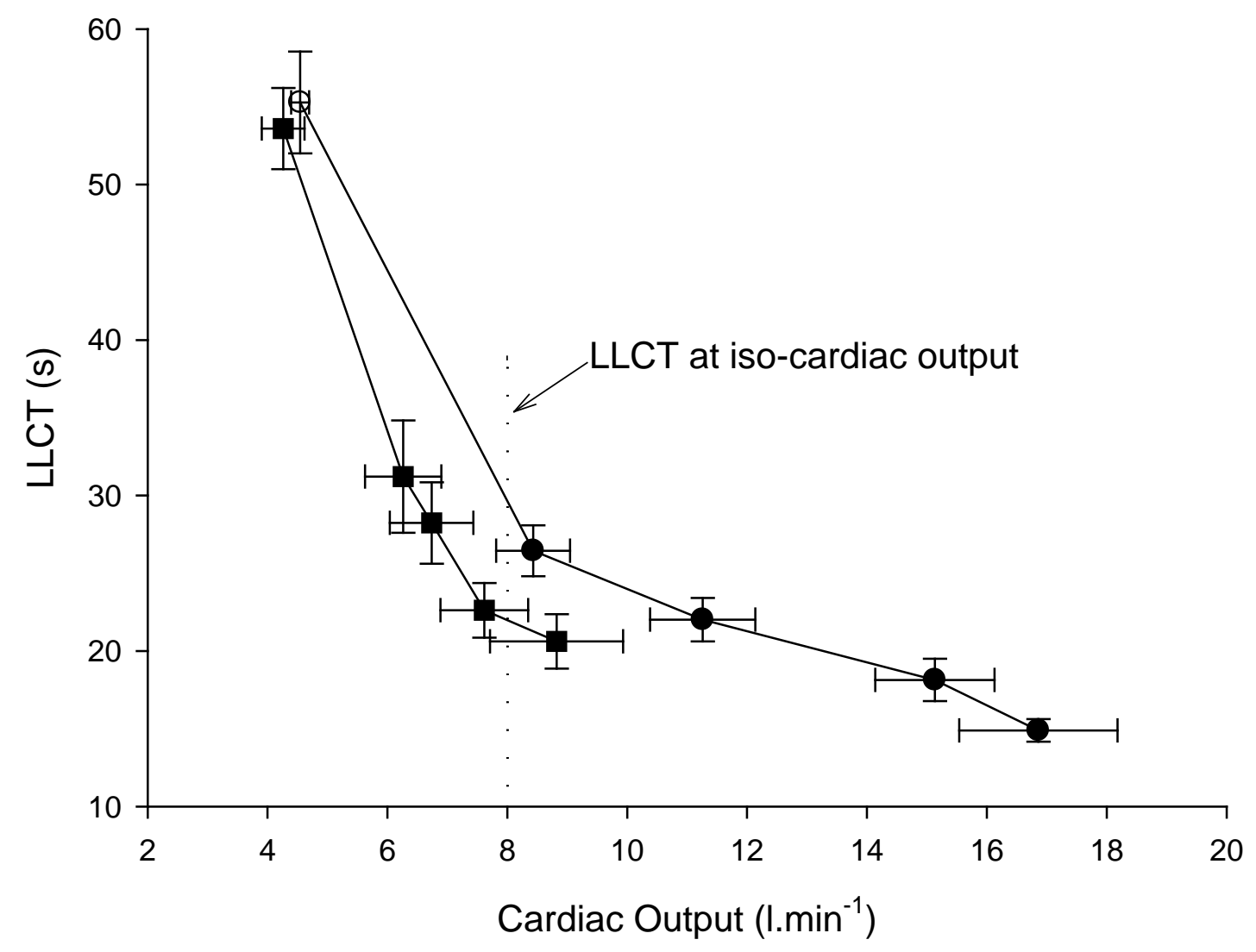

Figure 3 


\section{FIGURE LEGENDS}

\section{Figure 1.}

Changes in dependent measures a function of the percent power in Chronic Heart Failure (HF -) and Control $(\bullet)$ subjects. Panel A: LLCT (lung to lung circulation time); Panel B: Cardiac Output; Panel C: Functional blood volume; Panel D: SVR: Systemic Vascular Resistance. * $\mathrm{P}<0.05 \mathrm{HF}$ group significantly different from Control group.

\section{Figure 2.}

Correlations between LLCT, Q and vascular conductance during Stage 1 to peak exercise for Control (Panels A and B) and Heart Failure (Panels C and D) subjects. $(\bullet)$ Stage 1 exercise; (•) Stage 2 exercise; $(\bullet)$ Stage 3 Exercise; (x) Peak Exercise.

\section{Figure 3.}

Change in LLCT as function of the change in Q for the HF (Heart Failure $\mathbf{m})$ and control $(\bullet)$ groups. 
Table 1. Subject Characteristics for the Chronic Heart Failure and Healthy Control Group

\begin{tabular}{lcc}
\hline \hline & $\mathrm{HF}$ & Control \\
Age $(\mathrm{yr})$ & $53 \pm 14$ & $51 \pm 18$ \\
Male/Female & $7 / 3$ & $7 / 3$ \\
BMI $\left(\mathrm{kg} \cdot \mathrm{m}^{-2}\right)$ & $26.0 \pm 4.7$ & $24.5 \pm 2.4$ \\
MAP $(\mathrm{mmHg})$ & $76 \pm 9.2$ & $84 \pm 9.2$ \\
NYHA Functional Classes & $2.0 \pm 0.9$ & \\
Q (l.min $\left.{ }^{-1}\right)$ & $4.3 \pm 1.1$ & $4.5 \pm 0.5$ \\
Conductance $\left(\mathrm{ml} \cdot \mathrm{min}^{-1} \cdot \mathrm{mmHg}^{-1}\right)$ & $54 \pm 15$ & $53 \pm 14$ \\
Resting EF (\%) & $23 \pm 8$ & \\
LLCT (s) & $53.6 \pm 8.2$ & $55.3 \pm 10.9$
\end{tabular}

$\underline{\text { Cardiovascular Medications }}$

ACE/A-II Receptor Blocker $\quad$ 10/10

Digoxin $\quad 6 / 10$

Beta Blocker $\quad 9 / 10$

Diuretic $\quad 7 / 10$

Table 1. Results are mean \pm SD. HF: Chronic heart failure group. BMI: Body mass index; MAP: Mean arterial pressure; NYHA: New York Heart Association Classification; Q: Cardiac output; EF, Ejection Fraction; LLCT: lung-to-lung circulation time; ACE: Angiotensin-converting Enzyme Inhibitor; A-II: Angiotensin II. 
Table 2. Peak Exercise Responses and Chronic Heart Failure and Healthy Control Group

\begin{tabular}{lcc}
\hline \hline & $\mathrm{HF}$ & Control \\
$\mathrm{VO}_{2}\left(\mathrm{I} \cdot \mathrm{min}^{-1}\right)$ & $1.27 \pm 0.46^{\star}$ & $2.75 \pm 0.88$ \\
$\mathrm{HR}\left(\right.$ beats $\left.\cdot \mathrm{min}^{-1}\right)$ & $107 \pm 16^{\star}$ & $163 \pm 14$ \\
Power $(\mathrm{W})$ & $88 \pm 27^{\star}$ & $212 \pm 69$ \\
$\mathrm{Q}\left(\mathrm{I} \cdot \mathrm{min}^{-1}\right)$ & $8.8 \pm 2.5^{\star}$ & $16.9 \pm 1.3$ \\
$\mathrm{SV}\left(\mathrm{ml} \cdot \mathrm{min}^{-1}\right)$ & $78.1 \pm 10.8^{\star}$ & $102.6 \pm 27.2$ \\
$\mathrm{a}-\mathrm{V}_{\mathrm{O} 2} \mathrm{ml} \cdot \mathrm{dl}{ }^{-1}$ & $15.3 \pm 3.9$ & $16.2 \pm 2.6$ \\
MAP $(\mathrm{mmHg})$ & $92 \pm 15$ & $108 \pm 6.3$ \\
Conductance $\left(\mathrm{ml} \cdot \mathrm{min}^{-1} \cdot \mathrm{mmHg}^{-1}\right)$ & $103 \pm 28^{\star}$ & $148 \pm 36$ \\
LLCT (s) & $20.6 \pm 3.9^{\star}$ & $14.9 \pm 2.4$ \\
\hline
\end{tabular}

Table 2. Results are mean $\pm \mathrm{SD}$. $\mathrm{HF}$ : Chronic heart failure group. $\mathrm{VO}_{2}$ : Oxygen uptake; $\mathrm{HR}_{\text {peak: }}$ Peak heart rate; Q: Cardiac output; SV: Stroke volume: a-VO2: Arterio-venous oxygen difference. MAP: Mean arterial pressure; LLCT: Lung-tolung circulation time. ${ }^{*} \mathrm{P}<0.05$, HF group less than control group. 
Table 3. Hemodynamic changes during submaximal exercise stages in HF and healthy subjects

\begin{tabular}{llcccc}
\hline Stage & Group & $\begin{array}{c}\text { Power } \\
(\mathrm{W})\end{array}$ & $\begin{array}{c}\text { LLCT } \\
(\mathrm{s})\end{array}$ & $\begin{array}{c}\text { Q } \\
\left(\mathrm{I} \cdot \mathrm{min}^{-1}\right)\end{array}$ & $\begin{array}{c}\text { Conductance } \\
\left(\mathrm{ml} \cdot \mathrm{min}^{-1} \cdot \mathrm{mmHg}^{-1}\right)\end{array}$ \\
\hline Rest & HF & & $54 \pm 3$ & $4.3 \pm 0.1$ & $54 \pm 13$ \\
& Control & & $55 \pm 3$ & $4.5 \pm 0.1$ & $53 \pm 15$ \\
Stage 1 & $\mathrm{HF}$ & $21 \pm 5^{\star}$ & $31 \pm 4$ & $6.3 \pm 0.6$ & $80 \pm 18$ \\
& Control & $49 \pm 21$ & $26 \pm 1.6$ & $8.4 \pm 0.6$ & $90 \pm 16$ \\
Stage 2 & $\mathrm{HF}$ & $39 \pm 11^{*}$ & $28 \pm 3$ & $6.7 \pm 0.7^{*}$ & $84 \pm 14^{*}$ \\
& Control & $103 \pm 38$ & $22 \pm 1$ & $11.3 \pm 0.9$ & $115 \pm 31$ \\
Stage 3 & HF & $69 \pm 19^{*}$ & $23 \pm 2$ & $7.6 \pm 0.7^{*}$ & $89 \pm 14^{*}$ \\
& Control & $164 \pm 55$ & $18 \pm 1$ & $15.1 \pm 1.0$ & $141 \pm 26$ \\
\hline
\end{tabular}

Table 3. Results are mean \pm SD. HF: Chronic heart failure group; LLCT: Lung-tolung circulation time; Q: Cardiac output. * $\mathrm{P}<0.05, \mathrm{HF}$ group less than control group. 